\title{
GENDER DIFFERENCES IN THE RESPONSE TO COMPETITION JOSEPH PRICE
}

\begin{abstract}
I use the introduction of a competitive fellowship program for graduate students to test whether men and women respond differently to competition and whether this response depends on the gender mix of the group. Men experienced a $10 \%$ increase in performance in response to the program, with the largest gains for men in departments with the most female students. Women did not increase performance, on average, but the response of women did differ greatly depending on the gender mix of their peers, with a more positive response when a larger fraction of the group was female.
\end{abstract}

\footnotetext{
* Joseph Price is a PhD candidate in the Economics Department at Cornell University. The author wishes to thank Sharon Brucker, Ron Ehrenberg, Jeff Groen, Kevin Hallock, Lars Lefgren, Francesca Molinari, Harriet Zuckerman and participants at Cornell's TWIP seminar for helpful comments. Copies of the computer programs used to generate the results presented in this paper are available from Joseph Price at Department of Economics, Cornell University, Uris Hall $4^{\text {th }}$ floor, Ithaca, NY, 14853.
} 
A very small fraction of the top positions in both the private and academic sectors are occupied by women. For example, Bertrand and Hallock (2001) find that only $2.5 \%$ of the five highest paid executives in a large set of US firms are women. Several explanations have been provided for the under-representation of women in top positions. These include occupational self-selection, discrimination in hiring and promotion, and lack of long-term commitment to the workforce. ${ }^{1}$ An additional explanation, based on the experimental findings of several recent studies, is that men and women respond differently to competition and that this response to competition depends on the gender mix of the group.

The purpose of this paper is to extend these experimental results to a real life setting where the subjects are humanities graduate students at a set of highly ranked academic institutions. In 1991, the Mellon Foundation instituted the Graduate Education Initiative (GEI), with the explicit goal of providing funding on a competitive basis to students to encourage them to make quick progress towards completing their doctorate. The GEI provided $\$ 58$ million to 54 departments over a ten year period. The majority of the money was used by the departments to provide fellowships to students after they achieved certain hurdles, the first being advancement to candidacy. The individual departments decided which students to award the money to but the stated intent of the program was for the money to go to the students who made the quickest progress towards completing their degree.

\footnotetext{
${ }^{1}$ Blau and Kahn (2000) provide a review of the larger issue of the gender wage gap. Studies providing evidence for the explanations mentioned above include Polachek (1981) for occupational self-selection; Neumark (1996) for discrimination in hiring; and Cobb-Clark and Dunlop (1999) for discrimination in promotions.
} 
In the first few years of the GEI, the allocation of awards gave every appearance of being both very competitive (only $8 \%$ of students got the award) and very rewarding (recipients of the award experienced a $64 \%$ increase in their stipend). Ultimately the departments participating in the GEI did not allocate funds on a competitive basis, since most students eventually received an award (76\% of those who advanced to candidacy) and those who received the award early on did not receive more overall compensation than students who got the award latter in their studies. However, what is important for this analysis is that at least for a few cohorts of entering students, the GEI created the impression of being a very competitive program.

I use the introduction of this competitive fellowship program to test whether increasing within group competition affects men and women differently. While the setting does not provide any exogenous variation in the gender mix of each cohort, I do test whether the response to competition varies by the gender mix of one's peers. As an

additional extension, I also test whether the response differs based on the marital status of the student.

\section{Gender and Competition}

The use of competition as an incentive mechanism to increase performance has entered into many educational settings in the form of merit-aid or other rewards that are determined based on a student's performance relative to his or her peers. Nalbantian and Schotter (1997) find that within a firm, introducing inter-group competition is generally one of the cheapest ways to increase overall performance. Several recent papers, 
however, show that the response to competition may differ between men and women and that this response to competition may also depend on the gender mix of the group.

All of these recent papers are based on experimental settings in which participants compete in various tasks such as taking a difficult test (Inzlicht and Ben-Zeev 2000), solving mazes (Gneezy, Niederle, and Rustichini 2003), running a foot race (Gneezy and Rustichini 2004), or answering trivia questions (Antonovics, Arcidiacono, and Walsh 2004).

The first question addressed in these papers was whether men and women responded differently to the introduction of competition. Gneezy, Niederle, and Rustichini (2003) answer this question using a series of experiments in which college students are paid to solve mazes. They introduce competition in their experiment by switching from a piece-rate payment system to a tournament setting where the student who solves the most mazes (within a group of 6 participants) is the only one that receives money. They find that men always respond positively to the introduction of competition but women only respond positively to competition in groups composed entirely of women. Gneezy and Rustichini (2004) use running races of 9 and 10 year olds. In the first part of their experiment, each child runs alone. For the second race, students are paired based on their performance and raced again. Boys have large gains in performance when racing another child, especially if their competitor is a girl while girls experience no gain in performance when racing another student.

The second question addressed in these papers is whether the performance of men and women in competitive environments depends on the gender mix of the group. Antonovics, Arcidiacono, and Walsh (2004) find that men are more likely to answer a 
question correctly when a larger fraction of their competitors are women while women appear to be unaffected by the gender of their opponents. Inzlicht and Ben-Zeev (2000) carried out an experiment in which groups of three people take a difficult math and verbal test in the same room. The gender composition of the group is randomly assigned. The performance of men was not influenced by the gender mix of the group, but women did worse when a larger fraction of the group is male. As mentioned earlier, Gneezy, Niederle, and Rustichini (2003) find that women solve more mazes under a competitive pay-scheme when they are in groups with only women.

Gneezy, Niederle and Rustichini (2003) provide various explanations for why men and women respond to competition differently and why the response is influenced by the gender mix of the group. One explanation for why women respond less to competition is that the cost or increasing the level of effort may be greater. Another reason is that women may not like to compete (or the non-monetary benefits of competing are smaller). Niederle and Versterlund (2005) show that when given a choice, women are less likely to opt into a competitive setting compared to men. This aversion to competition may the result of women not being socialized to compete as much as men.

As to the influence of the gender mix of one's peers, if women believe (even if incorrectly) that men are better at the task, then a male and female student of equal ability may have different expectations about their relative ability to win the tournament. This expectation will affect the level of effort that they expend. There may also be evolutionary reasons why men are conditioned to "play harder" when more women are present. Some psychological explanations are that men may also face a higher psychological cost of "losing to a girl" while women may experience a stereotype threat 
that adds to their level of stress and decreases their performance (Steele 1997). Stereotype threat occurs when individuals from a group with which there is a stereotype of being less able at a certain task are reminded of the possibility of confirming the stereotype. For example, Spencer, Steele, and Quinn (1999) find that high-achieving women do worse on standardized math tests when the stereotype associated with girls and math is mentioned. Also Ulku-Steiner, Kurtz-Costes, and Kinlaw (2000) find that female students in male dominated departments have lower levels of self confidence.

The next section describes a program implemented by the Andrew Mellon Foundation that provides an interesting test of how adult men and women respond differently to competition in an educational setting and how this response differs based on the gender mix of a student's peers. An important thing to note is that all of the experimental studies were based on short-term responses to competition, whereas the program examined in this paper involved effort over an extended period of time. This type of extended competition is more relevant to the type of competitive schemes that are often devised for educational or workplace settings.

\section{Graduate Education Initiative}

The Andrew Mellon Foundation implemented the Graduate Education Initiative (GEI) in 1991 with the express goals of improving graduate education in the humanities and related social sciences by increasing graduation rates and decreasing time to degree. The Mellon Foundation chose ten institutions to participate it GEI because they tended to enroll the largest number of winners of portable Mellon fellowship program that had been in existence for a number of years. These institutions then selected 4-6 departments to 
participate in the GEI. The $\$ 58$ million was allocated across these departments during the years 1991-2001. An additional 47 control departments were chosen after the program was implemented. Some of these departments were from the GEI institutions while other came from other universities. The control departments are not entirely comparable to the treatment departments but the analysis in this paper controls for the observable measures of each department such as field, institution, student quality (GRE scores) and the number of students in each entering cohort. ${ }^{2}$

As part of their evaluation of the GEI, the Mellon Foundation collected data annually from both treatment and control departments on the funding (separately by tuition grant, fellowship, RA/TA funding, and Mellon awards) and progress of each student (including when they advanced to candidacy and when they either dropped out or graduated). The Mellon Foundation also collected information on student characteristics such as gender, race, citizenship, GRE math and verbal score, and whether the student had a master's degree before starting graduate school. In 2003, the Mellon Foundation administered a survey to all of the students who had entered one of the treatment and control departments which provides the age and marital status of the student at the start and end of graduate school. ${ }^{3}$ My sample includes the 9,664 students who entered one of the GEI or control departments between 1982 and 1995. Of these students, 7,321 completed the survey (76\% response rate). Table 1 provides summary statistics for the variables included in the analysis of this paper separately for men and women.

This data provide the three essential pieces of information needed to identify the gender differential in the response to competition: (1) the timing of a shock to the level of

\footnotetext{
${ }^{2}$ A complete list of the institutions and departments that were used as treatment and control schools as was as a more complete description of the GEI program is found in Groen et al. (2005).

${ }^{3}$ A more detailed description of the GEI survey is found in Ehrenberg et al. (2005).
} 
competition, (2) the fraction of a student's cohort that is female, and (3) a measure of student outcomes. The following sections briefly describe each of these measures.

\section{Shock to level of competition}

The introduction of the GEI provides the exogenous source of competition for the analysis in this paper. The GEI was announced by the Mellon Foundation in March 1991. It was the Foundation's intent that, "the departments will allocate the Foundation's grants on a competitive basis to individual students making good progress towards their degree." ${ }^{4}$ Students enrolled in Mellon departments were sent an explicit signal that the awards would be given on a competitive basis and that the primary criteria for these awards was that the student was making progress made towards one's degree (with advancing to candidacy being the first milestone).

Table 2 shows the amount of funding received by students who first entered GEI departments between 1987 and 1988. These are students who enrolled in GEI departments before the program was announced and who could have been eligible for GEI awards in the first year of the program. The numbers in the left column are the amount of funding received in 1990 and 1991 by students who did not receive a GEI award in 1991, while the right column provides the same information for the 154 students who received a GEI award in 1991. While the two groups of students were getting roughly equivalent levels of funding in 1990, the students who received the award experienced a significant increase in funding.

The results in table 2 show that the implementation of the GEI in 1991 sent three signals to students in the participating departments. Getting an award would significantly

\footnotetext{
${ }^{4}$ Andrew W. Mellon Foundation press release on March 25, 1991.
} 
increase your level of funding (on average $\$ 4,074$ or a $64 \%$ increase), only a minor fraction of students were getting the awards ( $8.36 \%$ in the first year), and the awards were being given to students who advanced to candidacy the quickest ( 2.48 years compared to 2.98 years). It turns out that none of these initial impressions were true in the long run for the GEI program. Most students eventually got a Mellon award (76\% of those who advanced to candidacy). Students who were the first to receive GEI awards received the same amount of money over the course of their studies as students who took longer to advance to candidacy. However, what is important for this analysis is that at least for a few cohorts of entering students, the GEI created the impression of being a very competitive program.

Thus the focus of this study is the set of students who entered graduate school between 1989 and 1990 (refereed to as majority-GEI). These students enrolled before the program was in place so there could have been no sorting with respect to a taste for competition. The students who entered graduate school between 1986 and 1988 (partialGEI) also fit this criteria but the majority of these students had already advanced to candidacy when the GEI was implemented, which would dilute the impact of the program on time to candidacy. Since the GEI awards were not to be given to students past their sixth year of enrollment, the entering cohorts of 1982-1985 (pre-GEI) were never eligible at any point for a GEI award. The primary analysis in this paper will be to compare the outcomes of the majority-GEI cohorts with the pre-GEI cohorts.

\section{Gender mix of entering cohort}


Slightly less than half of the students in the GEI sample are women. Table 3 provides the average cohort size and distribution of the gender mix of each cohort by field. The variation in gender mix makes it possible to test the differential response to competition over a continuous range of the fraction of the group that is female. I interact the fraction of students in a cohort who are female with the other variables of interest to test whether male and female students respond to competition differently when more of their classmates are female.

\section{Time to Candidacy}

The GEI was designed to provide fellowships to students who advanced to candidacy the quickest. As a result, the GEI created the highest levels of competition among students during the early years of graduate school. Using the time it takes students to advance to candidacy, therefore, provides a more direct test of the impact of competition than time to degree.

Table 4 provides the average time to candidacy, by gender, for both treatment and control departments. The first row in the table shows the time to candidacy of students who first entered the Ph.D. program between 1982 and 1985. The results show that for these pre-GEI cohorts, the students enrolled in GEI departments would advance to candidacy about one half year quicker than students enrolled at control departments $(2.86$ vs. 3.32 years for men and 3.02 vs. 3.45 years for women). The other rows in the first set of results report the average time to candidacy for the other time periods.

The second set of results in table 4 provide the difference in time to candidacy between students who enrolled in the partial, majority, or post-GEI periods and students 
who enrolled in the pre-GEI period. For example, the second row shows that men enrolled at control departments experienced an increase of .159 years in the average time to candidacy between the pre-GEI and majority-GEI periods, while men at GEI departments experienced a decrease of .292 years. The corresponding changes for women were a decrease of .122 years at control departments and a decrease of .166 years at GEI departments.

The third set of results in table 4 provide the difference between the change in time to candidacy at GEI departments that occurred between two periods with the change that occurred at control departments over the same time period. The table shows that men enrolled in GEI departments experienced a relative decrease of .451 years in the average time to candidacy between the majority-GEI and pre-GEI periods, while women enrolled in GEI departments experienced a relative decrease of only .044 years. These results are descriptive in nature but mimic the difference in difference estimation strategy used in the next section.

\section{Empirical Strategy and Results}

The impact of the GEI is estimated using the difference between the change in time to candidacy at GEI departments and the change in time to candidacy at control schools:

$$
\begin{aligned}
\text { Impact } & =\text { [Change in TTC at GEI depts.] - [Change in TTC at control depts.] } \\
& =\left[Y_{\text {majority, GEI }}-Y_{\text {pre, GEI }}\right]-\left[Y_{\text {majority, control }}-Y_{\text {pre, control }}\right]
\end{aligned}
$$


where $\mathrm{Y}$ is the time the student takes to advance to candidacy. The change at control departments captures the national level changes that would have likely influenced the GEI departments in the absence of the program.

The impact of the GEI can be estimated empirically using the following regression model:

$$
Y=\beta_{0}+\sum_{j=2}^{4} \beta_{1 j} \cdot \operatorname{period}_{j}+\beta_{2} \cdot G E I+\sum_{j=2}^{4} \beta_{3 j} \cdot \operatorname{period}_{j} \cdot G E I+\gamma \cdot X+\varepsilon
$$

where period refers to the time period in which the student entered graduate school (such as pre, partial, majority, and post).

Plugging in corresponding regression coefficients from equation (2) into equation (1) provides the following estimator for the impact of the program between the pre-GEI and the majority-GEI period:

$$
\begin{aligned}
\text { Impact } & =\left[\left(\beta_{0}+\beta_{13}+\beta_{2}+\beta_{33}\right)-\left(\beta_{0}+\beta_{2}\right)\right]-\left[\left(\beta_{0}+\beta_{13}\right)-\left(\beta_{0}\right)\right] \\
& =\beta_{33}
\end{aligned}
$$

The model in equation (2) is estimated separately by gender and the results are shown in table 5. The first two columns do not include controls for individual characteristics (prior masters degree, gre scores, race) while the second set of columns do. The point estimates that come from running the regressions separately by gender and are identical with those obtained using a pooled regression and interacting gender with all of the independent variables. The loss in precision of the standard errors is extremely small and so the regressions are run separately for the sake of clarity. Following the suggestion of Bertrand, Duflo, and Mullainathan (2004), standard errors are clustered at the cohort level (department/entering year). 
The results show that the GEI decreased time to candidacy for men by .47 years and had no effect on women. The impact of competition on men drops to .27 years when individual characteristics are controlled for but is still significant and represents a $10 \%$ decrease in the time to advance to candidacy. ${ }^{5}$

The second question I address is whether the response to competition by men and women differs based on the fraction of the cohort that is female. To answer this question, I interact the time period and treatment variable with measures of the fraction of a student's cohort that is female:

$$
\begin{aligned}
& Y=\beta_{0}+\sum_{j=2}^{4} \beta_{1 j} \cdot \text { period }_{j}+\beta_{2} \cdot G E I+\sum_{j=2}^{4} \beta_{3 j} \cdot \text { period }_{j} \cdot G E I+\beta_{4} \cdot \text { fraction female } \\
& +\beta_{5} \cdot G E I \cdot \text { fraction female }+\sum_{j=2}^{4} \beta_{6 j} \cdot \text { period }_{j} \cdot G E I \cdot \text { fraction female }+\gamma \cdot X+\varepsilon
\end{aligned}
$$

The variable fraction female is a measure of the fraction of a student's entering cohort that is female and is measured two ways. The first is a set of three indicators for whether female students make up fewer than $40 \%$ of the cohort (male-dominant), between 40 and $60 \%$ of the cohort (equally balanced), or more than $60 \%$ of the cohort (female-dominant). The second is a continuous measure of the fraction of the entering cohort that is female. The coefficient of interest is $\beta_{63}$ which comes from the interaction of being in a department that participated in the GEI, entering graduate school during the majority-GEI

\footnotetext{
${ }^{5}$ One concern in this analysis is that the GEI may have had a different impact on the attrition rates of men and women. For the majority-GEI group there was no significant change for men or women though the point estimate for men was more negative. For the post-GEI group men experienced a 6 percentage point decrease in attrition, while women experienced an insignificant increase of 2.7 percentage points. These findings would indicate that the results in this section understate the gender difference in response to the program since the male students that were prevented from dropping out are likely of a lower quality and as a result increased the time to candidacy of the men in the treatment sample.
} 
time period, and the fraction of the entering cohort that is female. The analysis is restricted to cohorts with at least 10 students.

The results in the upper panel of table 6 show that impact of competition on the performance of men is greatest in departments in which there is a larger fraction of female students with no significant impact in cohorts that are have fewer than $40 \%$ of the cohort being female. These results are consistent with the findings of Antonovics et al. (2005) that men perform better when more of their competitors are female. For women, the results indicate that there may be a slightly positive effect of competition in cohorts with a large fraction of students being women and a negative impact in male-dominant cohorts, though these results are only significant at the $10 \%$ level. The results in the lower panel in table 6 confirm the pattern of the non-linear effects that both and women have a more positive response to competition when a larger fraction of their peers are women.

A final question is whether the difference in the response of men and women to competition depends on their marital status. Marriage (and the children that often accompany it) provides incentives for students to use their time more effectively and puts married students under a tighter time constraint. Thus when competition is introduced, it is possible that married students have less excess capacity with which to increase effort and thus induces a smaller response.

Table 7 provides the same analysis as earlier but with the students separated by both gender and marital status at the start of graduate school. The results show that the only group that experienced a significant change in time to candidacy was single men who experienced a decrease of .20 years. Although not statistically significant, the GEI 
appears to have increased the time to candidacy of married women by .37 years. For both men and women, the GEI appears to have had a more positive effect (or less negative effect) on single students than married students.

\section{Conclusion}

The results in this paper show that men experienced a $10 \%$ decrease in time to candidacy in response to the introduction of the GEI, a competitive fellowship program, while women experienced no change, on average. Both men and women responded in a more positive way to the program when a larger fraction of their group was female. The results also suggest that the introduction of competition has a more positive impact on single students than married students.

These results indicate that when devising an incentive scheme for graduate students (and perhaps other work-related settings), there is an inherent tradeoff between increasing aggregate outcomes through the use of competition and achieving gender equity. By increasing the level of competition within a group, the average performance will increase but so may the gap in achievement between men and women. Future research might explore the degree to which the level of competition affects the gender wage gap within a particular occupation or industry. 


\section{References}

Antonovics, Kate; Peter Arcidiacono, and Randall Walsh (2004). "Competing Against the Opposite Sex." Unpublished Paper, UC San Diego.

Bertrand, Marianne; Esther Duflo, and Sendhil Mullainathan (2004). "How Much Should We Trust Differences-in-Differences Estimates?" Quarterly Journal of Economics, vol. 114, no. 1, pp. 249-275.

Bertrand, Marianne, and Kevin Hallock (2001). "The Gender Gap in Top Corporate Jobs." Industrial and Labor Relations Review, vol. 55, no. 1, pp. 3-21.

Blau, Francine, and Larry Kahn (2000). "Gender Differences in Pay." The Journal of Economic Perspectives, vol. 14, no. 4, pp. 75-99.

Cobb-Clark, Deborah and Yvonne Dunlop (1999). "The Role of Gender in Job Promotions." Monthly Labor Review, vol. 122, no. 12, pp. 32-38.

Ehrenberg, Ronald; George Jakubson, Jeffrey Groen, Eric So, and Joseph Price (2005). "Inside the Black Box of Doctoral Education: What Program Characteristics Influence Doctoral Student's Attrition and Graduation Probabilities?" NBER working paper 12065, March 2006.

Gneezy, Uri, Muriel Niederle, and Aldo Rustichini (2003). "Performance in Competitive Environoments: Gender Differences" The Quarterly Journal of Economics, vol. 20, no. 3, pp. 1049-1074.

Gneezy, Uri and Aldo Rustichini (2004). "Gender and Competition at a Young Age." The American Economic Review, vol. 94, no. 2, pp. 377-381.

Groen, Jeffrey; George Jakubson, Ronald Ehrenberg, Scott Condie, and Albert Liu (2005). "Program Design and Student Outcomes in Graduate Education." NBER working paper 12064, March 2006.

Inzlicht, Michael, and Talia Ben-Zeev (2000). “A Threatening Intellectual Environment: Why Females are Susceptible to Experiencing Problem-Solving Deficits in the Presence of Males." Psychological Science, vol. 11, no. 5, pp. 365-371.

Nalbantian, Haig and Andrew Schotter (1997). "Productivity Under Group Incentives: An Experimental Study.” American Economic Review, vol. 87, no. 3, pp. 314-341.

Neumark, David (1996). "Sex Discrimination in Restaurant Hiring: an Audit Study." Quarterly Journal of Economics, vol. 111, no. 3, pp. 915-941.

Niederle, Muriel and Lise Vesterlund (2005). "Do Women Shy Away from Competition? Do Men Compete Too Much?” NBER working paper 1474, July 2005. 
Polachek, Solomon (1981). "Occupational Self-Selection: A Human Capital Approach to Sex Differences in Occupational Structure." The Review of Economics and Statistics, vol. 63 , no. 1 , pp. 60-69.

Spencer, Steven, Claude Steele, and Diane Quinn (1999). "Stereotype Threat and Women's Math Performance.” Journal of Experimental Social Psychology, vol. 35, no. 1, pp. 4-28.

Steele, Claude (1997). "A Threat in the Air: How Sterotypes Shape Intellectual Identity and Performance." American Psychologist, vol. 52, no. 6, pp. 613-629.

Ulku-Steiner, Beril, Beth Kurtz-Costes, and C. Ryan Kinlaw (2000). "Doctoral Student Experience in Gender-Balanced and Male-dominated Graduate Programs." Journal of Educational Psychology, vol. 92, no. 2, pp. 296-307. 
Table 1. Summary statistics by gender

\begin{tabular}{lrrr} 
Student Characteristics: & Women & Men & $\begin{array}{r}\text { Women=Men } \\
\text { (t-stat) }\end{array}$ \\
\hline master's degree prior to entry & 0.203 & 0.234 & $\mathbf{3 . 6 8}$ \\
GRE verbal score & 670.5 & 671.3 & 0.48 \\
GRE math score & 616.6 & 647.0 & $\mathbf{1 6 . 5 4}$ \\
married at start of grad school & 0.185 & 0.232 & $\mathbf{4 . 9 5}$ \\
age at start of grad school & 25.86 & 25.93 & 0.56 \\
foreign student & 0.132 & 0.179 & $\mathbf{6 . 3 2}$ \\
minority student & 0.122 & 0.095 & $\mathbf{4 . 3 1}$ \\
non-minority student & 0.640 & 0.613 & $\mathbf{2 . 7 4}$ \\
time to candidacy & 3.021 & 2.856 & $\mathbf{7 . 5 2}$ \\
enrolled in Mellon department & 0.656 & 0.656 & 0.02 \\
& & & \\
Started program: & & & 1.93 \\
\hline pre (1982-85) & 0.228 & 0.245 & 0.38 \\
partial (1986-88) & 0.227 & 0.224 & 1.44 \\
majority (1989-90) & 0.170 & 0.159 & 0.26 \\
post (1991-95) & 0.375 & 0.372 &
\end{tabular}

Field:

\begin{tabular}{lllr}
\hline English & 0.282 & 0.176 & $\mathbf{1 2 . 4 7}$ \\
political science & 0.107 & 0.197 & $\mathbf{1 2 . 2 2}$ \\
history & 0.230 & 0.288 & $\mathbf{6 . 4 2}$ \\
other & 0.381 & 0.339 & $\mathbf{4 . 2 1}$ \\
& & & \\
Department: & & & \\
\hline entering cohort size & 15.85 & 16.50 & $\mathbf{3 . 3 6}$ \\
fraction Female & 0.535 & 0.411 & $\mathbf{3 6 . 7 9}$ \\
\hline $\mathrm{N}$ & 4,528 & 5,136 &
\end{tabular}

Notes: Bolded elements indicate a significant difference between men and women at the $5 \%$ level. 
Table 2. Funding levels, GEI awards, and time to candidacy for students who entered GEI departments in 1987-1988.

\begin{tabular}{|c|c|c|}
\hline & $\begin{array}{l}\text { Students who did not receive } \\
\text { a GEI-award in } 1991\end{array}$ & $\begin{array}{l}\text { Students who received a } \\
\text { GEI-award in } 1991\end{array}$ \\
\hline $\begin{array}{l}1990 \text { stipend } \\
\text { - includes RA, TA, and } \\
\text { fellowship funding }\end{array}$ & $\begin{array}{l}\$ 5,948 \\
(\$ 5,145)\end{array}$ & $\begin{array}{l}\$ 6,367 \\
(\$ 4,594)\end{array}$ \\
\hline $\begin{array}{l}1991 \text { stipend } \\
\text { - includes RA, TA, and } \\
\text { fellowship funding, as } \\
\text { well as GEI award }\end{array}$ & $\begin{array}{l}\$ 5,748 \\
(\$ 5,559)\end{array}$ & $\begin{array}{l}\$ 10,442 \\
(\$ 3,408)\end{array}$ \\
\hline $\begin{array}{l}1991 \text { GEI award } \\
\text { - included in } 1991 \text { stipend }\end{array}$ & $\$ 0$ & $\begin{array}{l}\$ 7,689 \\
(\$ 3,937)\end{array}$ \\
\hline Mean time to candidacy & $\begin{array}{l}2.977 \text { years } \\
(1.397)\end{array}$ & $\begin{array}{l}2.475 \text { years } \\
(.718)\end{array}$ \\
\hline $\begin{array}{l}\text { Percentage who advanced } \\
\text { to candidacy in less than } 3 \\
\text { years }\end{array}$ & $56.1 \%$ & $78.6 \%$ \\
\hline $\begin{array}{l}\text { Observations } \\
\text { [fraction of sample] }\end{array}$ & $\begin{array}{l}1,688 \\
{[91.6 \%]}\end{array}$ & $\begin{array}{l}154 \\
{[8.4 \%]}\end{array}$ \\
\hline \multicolumn{3}{|c|}{$\begin{array}{l}\text { Notes: The sample for this table are all of these students who enrolled in one of the GEI- } \\
\text { departments between } 1987 \text { and 1988. All monetary values are expressed in terms of } 1988 \\
\text { dollars. The difference in } 1990 \text { stipend level is not statistically different between the two } \\
\text { groups (t-stat=.957). All other differences are significant at the } 1 \% \text { level. Standard } \\
\text { deviations are reported in parentheses. }\end{array}$} \\
\hline
\end{tabular}


Table 3. Cohort size and fraction of students who are female.

\begin{tabular}{|c|c|c|c|c|c|c|c|}
\hline \multirow[b]{2}{*}{ Field } & \multirow{2}{*}{$\begin{array}{l}\text { cohort } \\
\text { size }\end{array}$} & \multirow{2}{*}{$\begin{array}{l}\text { fraction } \\
\text { female }\end{array}$} & \multicolumn{5}{|c|}{ Percentiles for fraction female: } \\
\hline & & & $10^{\text {th }}$ & $25^{\text {th }}$ & $50^{\text {th }}$ & $75^{\text {th }}$ & $90^{\text {th }}$ \\
\hline Anthropology & 10.13 & 0.573 & 0.333 & 0.500 & 0.590 & 0.667 & 0.765 \\
\hline Art & 8.99 & 0.664 & 0.500 & 0.500 & 0.667 & 0.750 & 0.833 \\
\hline Classics & 5.30 & 0.449 & 0.250 & 0.286 & 0.423 & 0.600 & 0.714 \\
\hline Comp. literature & 8.11 & 0.579 & 0.333 & 0.444 & 0.571 & 0.680 & 0.800 \\
\hline English & 20.53 & 0.594 & 0.405 & 0.508 & 0.598 & 0.667 & 0.760 \\
\hline History & 25.41 & 0.438 & 0.296 & 0.368 & 0.444 & 0.526 & 0.600 \\
\hline Music & 8.87 & 0.409 & 0.176 & 0.286 & 0.400 & 0.500 & 0.667 \\
\hline Philosophy & 8.11 & 0.299 & 0.125 & 0.222 & 0.286 & 0.400 & 0.500 \\
\hline Political science & 18.21 & 0.345 & 0.200 & 0.267 & 0.333 & 0.429 & 0.514 \\
\hline Religion & 8.08 & 0.427 & 0.200 & 0.273 & 0.429 & 0.600 & 0.667 \\
\hline Sample & 13.57 & 0.488 & 0.250 & 0.333 & 0.500 & 0.625 & 0.740 \\
\hline
\end{tabular}

Notes: Cohort size refers to the number of students that enter a specific department in a particular year. Fraction female refers to the fraction of students in each field that are female. The percentiles report the fraction of students that are female in the cohort that is the $\mathrm{X}^{\text {th }}$ percentile in terms of fraction of students being female. 
Table 4. Average Time to candidacy by treatment, gender, and time period

\begin{tabular}{lrrrr} 
& \multicolumn{3}{c}{ Men } & Women \\
\hline Started program: & Control & GEI & Control & GEI \\
\hline 1982-85 (pre) & 3.320 & 2.856 & 3.449 & 3.024 \\
$1986-88$ (partial) & 3.494 & 2.672 & 3.501 & 2.854 \\
$1989-90$ (majority) & 3.479 & 2.564 & 3.327 & 2.858 \\
$1991-95$ (post) & 3.271 & 2.630 & 3.319 & 2.780 \\
& & & & \\
Difference & & & & \\
\hline partial - pre & 0.174 & -0.184 & 0.052 & -0.170 \\
majority - pre & 0.159 & -0.292 & -0.122 & -0.166 \\
post - pre & -0.049 & -0.226 & -0.130 & -0.244
\end{tabular}

Difference in Difference:

$\Delta$ GEI - $\Delta$ Control

\begin{tabular}{lll}
\hline$\Delta=($ partial - pre $)$ & -0.358 & -0.222 \\
$\Delta=($ majority - pre $)$ & -0.451 & -0.044 \\
$\Delta=($ post - pre $)$ & -0.177 & -0.114
\end{tabular}

Notes: GEI refers to students who enrolled in a department that participated in the GEI. "Pre" refers to students who were never eligible for a GEI award at any point in graduate school. The majority group is the focus for this study since they were the students who were enrolled but had not yet advanced to candidacy when the program was implemented in 1991. 
Table 5. Impact of GEI on time to candidacy by gender

\begin{tabular}{|c|c|c|c|c|}
\hline & women & men & women & men \\
\hline pre & -- & -- & -- & -- \\
\hline \multirow[t]{2}{*}{ partial } & 0.097 & 0.186 & 0.003 & -0.028 \\
\hline & {$[0.157]$} & {$[0.133]$} & {$[0.085]$} & {$[0.078]$} \\
\hline \multirow[t]{2}{*}{ majority } & -0.132 & 0.186 & $-0.265 * *$ & -0.016 \\
\hline & {$[0.157]$} & {$[0.131]$} & {$[0.093]$} & {$[0.080]$} \\
\hline \multirow[t]{2}{*}{ post } & -0.127 & -0.027 & $-0.277 * *$ & -0.136 \\
\hline & {$[0.126]$} & {$[0.114]$} & {$[0.078]$} & {$[0.071]$} \\
\hline \multirow[t]{2}{*}{ GEI } & $-0.376^{* *}$ & $-0.438 * *$ & 0.160 & $0.220 * *$ \\
\hline & {$[0.129]$} & {$[0.131]$} & {$[0.096]$} & {$[0.082]$} \\
\hline \multirow[t]{2}{*}{ GEI.partial } & -0.273 & $-0.357 *$ & -0.177 & -0.131 \\
\hline & [0.192] & {$[0.180]$} & [0.109] & {$[0.101]$} \\
\hline \multirow[t]{2}{*}{ GEI·majority } & -0.028 & $-0.474^{*}$ & 0.094 & $-0.269 *$ \\
\hline & [0.194] & [0.189] & {$[0.120]$} & {$[0.106]$} \\
\hline \multirow[t]{2}{*}{ GEI·post } & -0.122 & -0.186 & -0.005 & -0.131 \\
\hline & [0.159] & {$[0.157]$} & {$[0.100]$} & {$[0.092]$} \\
\hline \multirow[t]{2}{*}{ cohort size } & & & $-0.005^{*}$ & $-0.006^{* *}$ \\
\hline & & & {$[0.002]$} & {$[0.002]$} \\
\hline \multirow[t]{2}{*}{ masters degree } & & & $-0.336 * *$ & $-0.343 * *$ \\
\hline & & & {$[0.043]$} & {$[0.037]$} \\
\hline \multirow{2}{*}{ GRE verbal score } & & & 0.009 & -0.022 \\
\hline & & & {$[0.018]$} & {$[0.015]$} \\
\hline \multirow[t]{2}{*}{ GRE math score } & & & $-0.052 * *$ & -0.021 \\
\hline & & & {$[0.016]$} & {$[0.014]$} \\
\hline \multirow[t]{2}{*}{ foreign student } & & & $-0.123 * *$ & $-0.096 * *$ \\
\hline & & & {$[0.044]$} & {$[0.033]$} \\
\hline \multirow[t]{2}{*}{ minority student } & & & $0.076 *$ & $0.101 *$ \\
\hline & & & [0.039] & [0.041] \\
\hline \multirow[t]{2}{*}{ constant } & $3.389 * *$ & $3.243 * *$ & $3.152 * *$ & $3.006 * *$ \\
\hline & {$[0.108]$} & {$[0.094]$} & {$[0.184]$} & [0.169] \\
\hline $\mathrm{N}$ & 4,528 & 5,136 & 4,528 & 5,136 \\
\hline $\mathrm{R}^{2}$ & 0.05 & 0.09 & 0.39 & 0.44 \\
\hline
\end{tabular}

Notes: Pre, partial, majority, and post refer to the year the student entered graduate school. GEI indicates the student was enrolled in a department that participated in the program. The model also includes controls for field and institution. Standard errors are clustered to account for general autocorrelation among errors across students within the same cohort (department/entering year). We use asterisks to denote statistical significance as follows: *statistically significant at the .05 level; **at the.01 level. 
Table 6. Impact of GEI on time to candidacy by student gender and gender mix of cohort

\begin{tabular}{|c|c|c|c|}
\hline Non-linear Effect & women & men & $\begin{array}{l}\text { women } \\
\text { (t-stat) }\end{array}$ \\
\hline \multicolumn{4}{|c|}{ (GEI - majority) interacted with: } \\
\hline male dominant & $\begin{array}{l}0.399 \\
{[0.311]}\end{array}$ & $\begin{array}{l}-0.043 \\
{[0.194]}\end{array}$ & $1.70 *$ \\
\hline equally balanced & $\begin{array}{l}0.252 \\
{[0.220]}\end{array}$ & $\begin{array}{l}-0.346 \\
{[0.184]}\end{array}$ & $2.72 * *$ \\
\hline female dominant & $\begin{array}{l}-0.261 \\
{[0.207]}\end{array}$ & $\begin{array}{l}-0.997 * * \\
{[0.313]}\end{array}$ & $2.25 *$ \\
\hline $\begin{array}{l}\mathrm{N} \\
\mathrm{R}^{2}\end{array}$ & $\begin{array}{l}3,576 \\
0.42\end{array}$ & $\begin{array}{l}4,057 \\
0.46\end{array}$ & \\
\hline
\end{tabular}

\section{Linear Effect}

(GEI $\cdot$ majority) interacted with:

$\begin{array}{llll}\text { fraction of cohort that is female } & -1.82^{*} & -1.64^{*} & 0.19 \\ & {[0.867]} & {[0.649]} & \\ & & \\ \mathrm{N} & 3,576 & 4,057 \\ \mathrm{R}^{2} & 0.41 & 0.46\end{array}$

Note: The test statistic is based on a pooled regression and involves testing for a difference in the interaction between female and the coefficient listed. Each model includes all the variables from the right two columns in table 5 including field and institution controls. Each model also includes the main effects for male dominant, equally balanced, and female dominants along with their interaction with partial, post, and GEI. The analysis is limited to cohorts with at least 10 students. We use asterisks to denote statistical significance as follows: *statistically significant at the .05 level; **at the.01 level. 
Table 7. Impact of GEI on time to candidacy by gender and marital status

\begin{tabular}{lcccc} 
& Single men & Married men & Single women & Married women \\
\hline partial & -0.086 & -0.142 & 0.035 & -0.001 \\
& {$[0.094]$} & {$[0.137]$} & {$[0.099]$} & {$[0.179]$} \\
majority & -0.062 & -0.068 & $-0.259 *$ & $-0.462^{*}$ \\
& {$[0.096]$} & {$[0.144]$} & {$[0.110]$} & {$[0.190]$} \\
post & $-0.176^{*}$ & -0.169 & $-0.287 * *$ & -0.198 \\
& {$[0.088]$} & {$[0.137]$} & {$[0.093]$} & {$[0.160]$} \\
GEI & 0.136 & 0.133 & 0.101 & 0.153 \\
& {$[0.104]$} & {$[0.155]$} & {$[0.113]$} & {$[0.194]$} \\
GEI·partial & -0.037 & -0.107 & -0.207 & -0.098 \\
& {$[0.122]$} & {$[0.167]$} & {$[0.124]$} & {$[0.215]$} \\
GEI·majority & -0.204 & -0.118 & 0.081 & 0.373 \\
& {$[0.128]$} & {$[0.190]$} & {$[0.136]$} & {$[0.243]$} \\
GEI·post & -0.104 & 0.047 & 0.006 & -0.086 \\
& {$[0.113]$} & {$[0.164]$} & {$[0.114]$} & {$[0.197]$} \\
constant & $3.179 * *$ & $2.774 * *$ & $3.498 * *$ & $2.864 * *$ \\
& {$[0.217]$} & {$[0.331]$} & {$[0.232]$} & {$[0.419]$} \\
\hline $\mathrm{N}$ & 2,959 & 894 & 2,883 & 655 \\
$\mathrm{R}^{2}$ & 0.48 & 0.39 & 0.41 & 0.39
\end{tabular}

Notes: The measure of marriage here is based on the student's marital status at the start of graduate school and does not account for students who get married during graduate school. We use asterisks to denote statistical significance as follows: *statistically significant at the .05 level; **at the.01 level. 